\title{
Identifying Research Dimensions from the Outlook of Faculty Members of the Islamic Azad University of Dezful
}

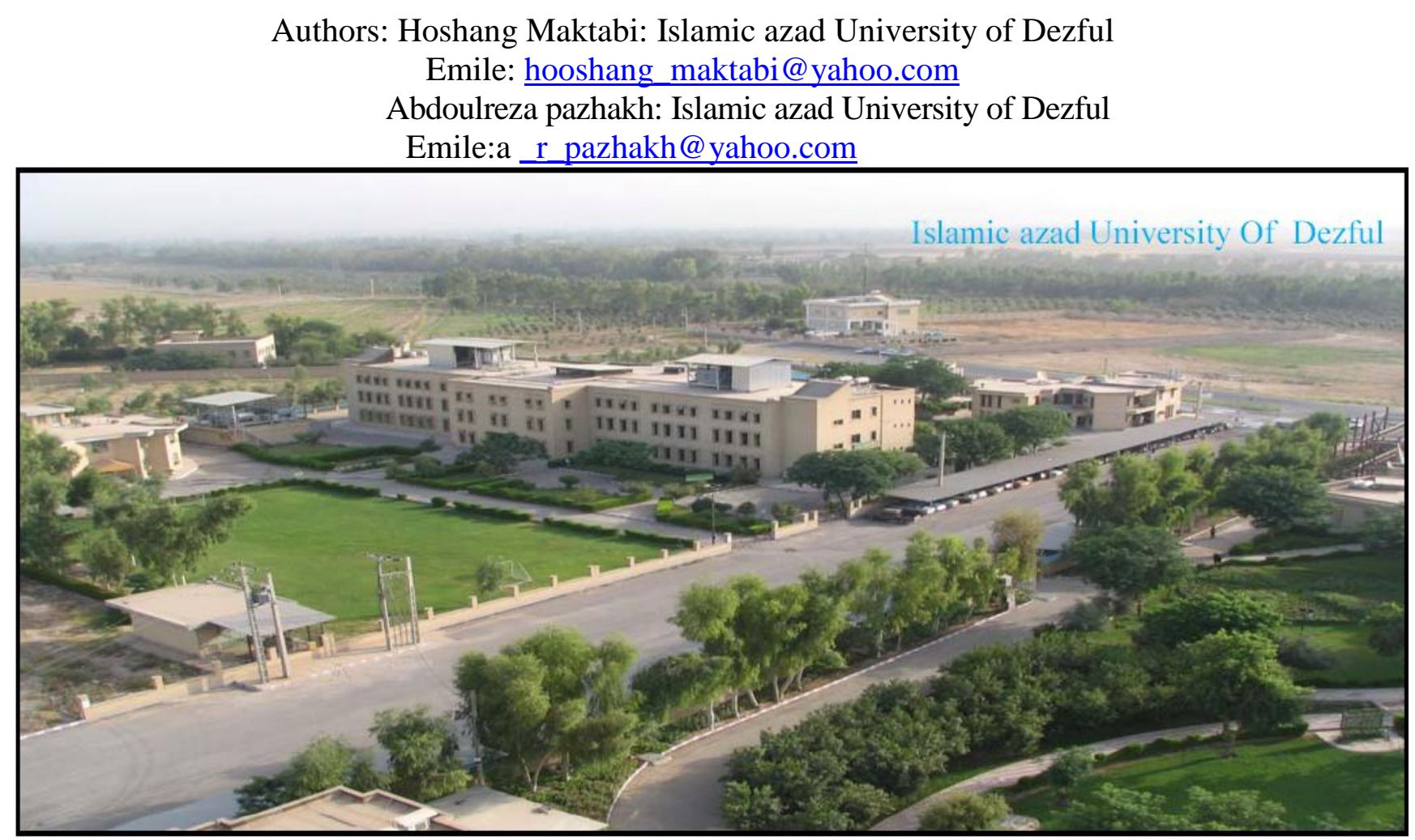

\section{Abstract}

Today, research and development (R\&D) are included among the important global issues. What makes research important is innovation in science and opening new horizons for solving human problems. $\mathrm{E}$ the other hand, higher education, functioning as a propelling force of a country particularly in training and specializing human forces, is expected to attend to this issue more than any other system. To analogize the relationship between the quality and efficiency of higher education, one can refer to the fact that the higher the quality of a research is, the more satisfied the researchers and the more useful the research will be. To achieve this objective, the important and basic elements of an acceptable research should be determined so that researchers and authorities can deal with these issues more carefully. In this research, using statistical procedures, we have tried to determine the dimensions of quality of a research from the view point of more than 700 faculty members of the Islamic Azad University of Dezful. Finally, to follow the paradigm used by Zetammel, four dimensions of the research quality were determined to be dealt with deeply and more importantly than others.

Key words: global issues, propelling force, efficiency, higher education, statistical procedures, paradigm, dimensions of research quality 


\section{Introduction}

Man with his needs and curiosity faces certain barriers and questions in his daily life. To find a way to tackle those problems and to develop more and more, he makes different attempts, forms various hypotheses and uses different strategies varying from the simplest to the most complex ones. In effect, this is where one can maintain that each problem with which one is faced, or each question raised by man followed by attempts to solve it all imply what we term here as research. The significance of research and its basic role in developing the current societies is an essential issue, particularly the researches in which orientations and general strategies could have changed the higher educational system. And a considerable number of experts and researchers are trying to establish and spread the new social values, relations and structures. However, what is more important than the research itself is the type of attitude one adopts towards research, the pertinent analyses, and the skill to put them into practice. In fact, from the distinctive features and the advantages of this approach to research is the superiority of thought to action, or research to personal or social sides-taking. That is why the answer to the following question is so easy: Why haven't researches, though extensive in number, resolved any special problem but they have even created more doubts and confusions? Yet, we should consider that approaches and research methods, in their own turn, comprise part of human's understanding. Then, along with the development of sciences and technology, attitudes and socially-domintaed values have changed and become developed and more and more complicated.

These days, many organizations and big centers are doing extensive researches, and are constantly reviewing and revising their approaches to improving them. Indeed, they are making attempts to carefully recognize and apply the current approaches, and also looking for new approaches to research and analysis as important steps towards the development of research procesiin a scientific community. This is nothing but promoting the quality of research that is, meeting the needs of users. In this research, using statistic procedures, attempts have been made to put different dimensions of research in scope. It is emphasized that the research objective has not been set to measure the quality of the research but to determine the dimensions of a research in line with Zeta Mel and Paraguayan.

\section{Review of Literature}

This research measures the quality of research if it is defined as 'the satisfaction of customer' of the research. It practically targets the research output, and is finally evidenced in desired situations and as we know the number of evidences indicates a research high validity and function. Today, there have been numerous studies regarding the elements of the quality of research some of which will be referred to.

\section{2-1. Dr. Bagher Sarokani's study}

In the second section of his research book (2004), this author refers to the basic components of research as:

\section{- Concepts}


- Hypothesis (which is generally a pre-planned question about a real thing) whether to access new rules or relations or to see if the previously known rules are applicable or not Kinds of hypothesis include: biased or non-biased descriptive, multivariable, simple, analytic, limited and null

- Variables are characteristics or attributes which may change in quality or quantity. Different variables are: nominal, ordinal, independent and dependent, controlled, continuous and separate

- The research plan which is an important component of the research are divided into simple and credential

- Sampling: any series of things or phenomena and whatever which can represent a whole is called a sample

\section{2-2. Dr. Graeme's Study:}

This author refers to the most important dimensions of research and mentions:

- Parameters related to the researcher himself or herself which include knowledge, internal aspects, habits, emotions and spiritual interests;

- $\quad$ The team members and their personal characteristics;

- $\quad$ Sources of the research and their rarity;

- $\quad$ Political, social, and cultural limitations.

\section{2-3. Groot et al's stud":}

This author, in a part of his study, describes the different parameters between the quality of research output and its usefulness as:

- $\quad$ size of the research group

- $\quad$ composition of the staff

- $\quad$ sources of research funding

- $\quad$ academic discipline

\section{2-4 Todd Littman's study}

In an article about evaluating the quality of research in 2007 in Canada, this author considers research as seeking the usefulness of knowledge which can also be destructive. He counts the characteristics of a good research as the following:

- $\quad$ suitable definition of research questions

- background explanation and output information about a subject 
- observing the different aspects of a research

- offering reasons and their clarity using the data and analyzing them in an appropriate format

- discussing the critical hypotheses, discovering counter-arguments and explaining the replacements

- cautious and peripheral (references)

- adequate sources and references

He also considers the evaluating strategies of a documentary research as:

- It is posed justly and fairly from every aspect

- precision in questions definitions and their relation to the topic

- creating a logical connection between the results and arguments

- $\quad$ preparing suitable and desired sources

- $\quad$ explaining the limitations and analyzing them

- It is respected from every perspective for the people

2-5. Tony Brinn, Michael John Jonesin, England in 2000

Give a point to survey a research by an experienced person and give zero point to survey a research through quotation.

\section{Methodology}

In this research, the participants arjall the faculty members of the Islamic Azad University of Dezful located in region number six currently (2007-2008) teaching in the university who have at least carried out one research or an accepted essay in or outside Iran and their records according to the latest assessment amount to 700 .

According to Morgan- Kerjsay table, the sample number is 248 who have been selected randomly.

The steps of carrying out the research follow as:

- Collecting data using scientific sources, reliable journals, essays and experiences of the masters in the field.

- Preparing the first questionnaire using the ideas of Morgan in order to justify and modify I and eventually making the questionnaire ready with 32 items. 
- Conducting the questionnaire for 206 of the statistic sample in order to find the general dimensions and omitting the extra items with the factorial load less than .356 using strong factorial analysis and using SPSS software.

- Finding first hypotheses in the general dimensions of research quality and omitting four items and preparing the questionnaire with 28 items in order to validate the questionnaire through concurrent validity.

- Conducting the final questionnaire for 248 people (distributing 350 copies)

- Using factorial analysis and finding the dimension of research quality.

\section{Validity and Reliability:}

4-1. In order to validate the research, the two procedures of Content validity and Structural validity were used.

Since in data collection and preparing the questionnaire, the masters of the field were involved, and items were primarily treated in several introductory steps, then the content validity of the questionnaire was confirmed. And in order to re-evaluate the questionnaire, concurrent validity was also used (the result are included). Pearson coefficient indices showed the desirable validity of the questionnaire.

${ }^{4}-2$. In order to certify the reliability of the questionnaire and in other words the constancy of results in case of repeating the experiment, the Cronbach statistic $(\alpha=\% 884)$ was used which is a proper reliability for the questionnaire.

\section{Con c l u s i o n}

\section{5-1. Means of the items}

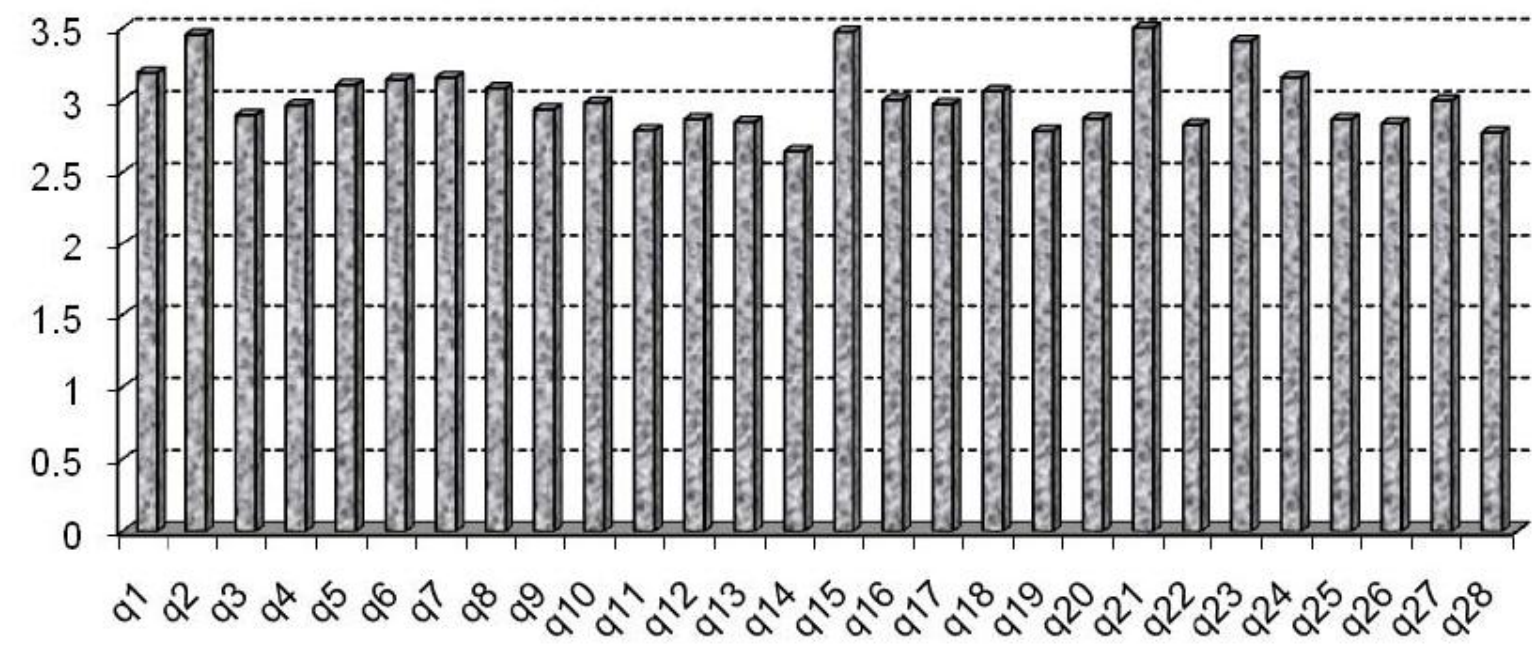

Graph no. 1 
As it was observed in Graph1 (the means of the items in the questionnaire), the first three items have the highest means which are as follows: item number 21 with the topic "interest in research" with the mean of 3.63 which shows the importance of motivation to encourage the professors towards research; item number 15 with the topic "researcher's familiarity with a foreign language' with the mean of 3.47, which shows the importance of knowing foreign languages; and finally item number 2 with the topic "digital and written sources available to the researcher" with the mean of 3.45 which shows the importance of these sources to the researcher. In this regard, Islamic Azad University of Dezful, having a digital library and an expending more than 360000000 Rials yearly (equal to 24000 euros), has created a suitable condition for its professors in order to do their researches. Meanwhile, the lowest mean was related to item number 14 with the topic "the type of topic in terms of kinds of disciplines" with the mean of 2.64 which shows that kinds of sciences have the smallest effect on the quality of research.

\section{5-2. Determining the Factors}

Using the strong statistical procedure of factorial analysis in order to determine the research dimensions and considering Scree (Graph number 2), fourjactors were determined as follows:

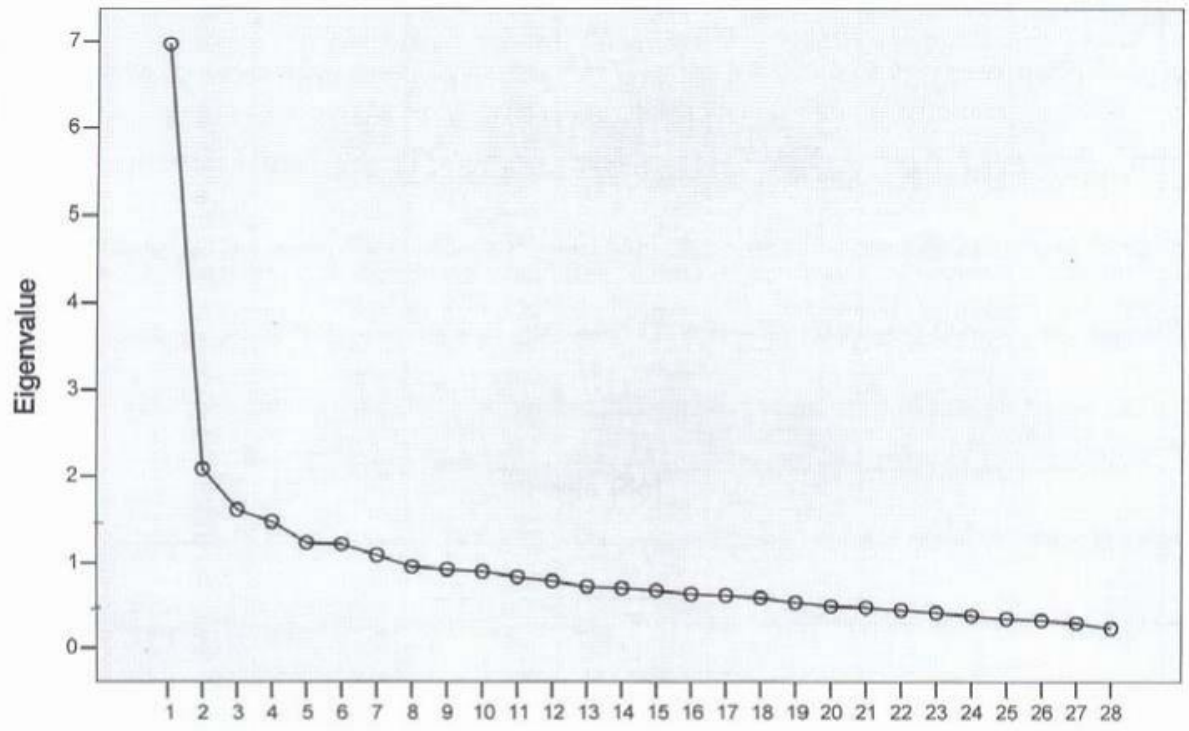

Graph no.2

Factor number:

- "Financial issues, and office rituals" consisting of 9 items, cases like payment of research projects and other incomes of the researcher, preferring official-educational work to doing research, ...

- Personal characteristics of the people involved in the research consisting of 8 items, cases like the researcher's interest, the researcher's familiarity with foreign language, the referees, ... 
- Factors related to the skills and procedures of research consisting of 3 items, cases like the research method, and research statistic sample, ...

- $\quad$ The other research materials consisting of 3 items.

Five items were omitted because of having a low factorial load.

Then we have a 23 item questionnaire with an acceptable validity and reliability which accords with the previous findings.

\section{5-3. Comparison between men and women's opinions}

Using a t-test, no significant difference was observed.

\section{5-4. Comparison of ideas among the professors of different fields}

Since from the total 248 professors 144 were from humanities and 104 were from engineering and basic sciences, a t-test was used to compare their opinions. The test showed no significant difference between their opinions.

\section{References}

1. Kavosi-Mohammad Reza, Abbas Saghaei, "Customer Satisfaction Measurement Methods", ISBN 964-8249-11-3, Tehran, 2004.

2. Qaemi Ali, "Methodology of Research", ISBN, 1988, Tehran.

3. Sarookhani, " Methodology of Research", ISBN 946-424-23-6, 2004, Tehran

4. C.A Moser and ghalton: SDurvey Methods in Social Investigation

5. Robert K. in : "Case Study Research", ISBN 964-5799-69-4 , 2000

6. Tom Groot, Teresa Garcia-Valderrama, "Research Quality and Efficiency- An analysis of assessments and management issues in Dutch economics and business research programs", Research Policy 35 (2006) 1362-1376.

7. Todd Littman. "Evaluating Research quality" Guidelines for scholarship, Victoria transport policy institute 19 November 2007 Canada. 